Article

\title{
Modelling of Grain Size Evolution with Different Approaches via FEM When Hard Machining of AISI 4140
}

\author{
Berk Tekkaya ${ }^{1, *, \dagger}$, Markus Meurer ${ }^{2}$ and Sebastian Münstermann ${ }^{1,+}$ \\ 1 Integrity of Materials and Structures (IMS), Department of Ferrous Metallurgy (IEHK), \\ RWTH Aachen University, 52072 Aachen, Germany; Sebastian.Muenstermann@iehk.rwth-aachen.de \\ 2 Laboratory for Machine Tools and Production Engineering (WZL), RWTH Aachen University, \\ 52074 Aachen, Germany; M.Meurer@wzl.rwth-aachen.de \\ * Correspondence: berk.tekkaya@iehk.rwth-aachen.de; Tel.: +49-241-80-25426 \\ + Intzestraße 1, 52072 Aachen, Germany.
}

Received: 2 September 2020; Accepted: 24 September 2020; Published: 28 September 2020

check for updates

\begin{abstract}
Thermo-mechanical loads during hard turning lead to the formation of so-called White Layers on the machined surface. Characterized by a very fine microstructure and high hardness, White Layers have a negative effect on the fatigue life of a component. The fundamental mechanism for the White Layer formation is the dynamic recrystallization (DRX). Therefore, in the current work, two different DRX models, Helmholtz free energy and Zener-Hollomon, are implemented into Abaqus/Explicit to predict the thickness of the White Layer when hard turning quenched/tempered AISI 4140 and the results are compared with each other. For the simulation of the machining process a Finite Element Method (FEM) model based on the Coupled-Eulerian-Lagrangian (CEL) method is built up. Although both DRX models achieved a very good match between predicted and measured White Layer thickness and grain size evolution on the workpiece rim zone, the Zener-Hollomon model produced more closer agreement.
\end{abstract}

Keywords: Surface Integrity; White Layer; DRX; FEM; orthogonal cutting

\section{Introduction}

$\mathrm{Cr} / \mathrm{Mo}$-alloyed steels are mainly used in the automotive and aviation constructions due to their high strength combined with high toughness. For example, AISI 4140 steel (42CrMo4 in Europe) in quenched/tempered condition has a hardness of approximately $48 \mathrm{HRC}$ in addition to their high strength and toughness, which make this type of material challenging to machine. At this point, hard turning can be considered as a possible material removal process [1] and provides many advantages, among them are direct machining of the workpiece in hardened state, higher flexibility and cutting performance and requiring no grinding [2,3]. High temperatures, strains and strain rates that occur during hard machining, on the other hand, can be regarded as disadvantages which make this process highly interesting for research on Surface Integrity (i.e., general term for microstructural alternations, residual stress states, hardness, chemical decomposition and corrosion resistance on the workpiece rim zone) $[4,5]$.

According to the detailed literature review by Jawahir et al. [5] and the recent research of Borchers et al. [6] about Surface Integrity in machining, the functionality and fatigue life of a machined part is strongly related to its topographical, metallurgical and mechanical properties in the rim zone. Hard turning is known for the induced thermo-mechanical loads that lead to altered microstructures, hardness, residual stresses, dislocation densities and grain sizes at the surface layers. 
Typical thermo-mechanical related microstructural modifications are the White and Dark Layers $[7,8]$. Specifically, White Layer is a layer which has a few microns of thickness. It is characterized by a hard and brittle structure [8-10]. In contrast, Dark Layer is identified as a soft and ductile structure with a higher thickness than White Layer (20-40 microns) [10]. The combination of White and Dark Layers can significantly reduce the fatigue life, due to the inhomogeneous stress distributions at cyclic loads $[2,3,11]$. White Layers pose a high probability of formation and propagation of crack $[12,13]$, while dark layers influence the magnitude and location of the residual stresses [10]. Griffiths summarized the three main theories for the White Layer formation; dynamic recrystallization (DRX) (severe plastic deformation), phase transformation (rapid heating and quenching) and surface reaction with the environment [7]. Dark Layer, however, is formed due to the microstructural changes triggered in the heat affected zone during the hard turning [14].

Most recent study by Fang-yuan et al. investigated the microstructure, phase transformation and carbon distribution of White and Dark Layers when machining AISI 52100 steel to understand their formation mechanisms [15]. They found that White Layer formation is related to rapid austenite transformation and quenching process, while Dark Layer formation is caused by a tempering process. They also showed that the carbon and chromium concentrations are different in White (the highest) and Dark Layers (the lowest).

In another recent study, Brown et al. focused on the characterization of super chrome molybdenum vanadium steel in terms of Surface Integrity (White Layer formation) [16]. They showed that in their case White Layer formation is triggered by severe plastic deformation, not by phase transformation, as demonstrated by the missing retained austenite peaks in the X-ray diffraction patterns and compressive residual stress profiles.

For many years, several researchers have been using different approaches to investigate machining-induced surface modifications, microstructural changes and grain size development. The most common ones are based on the following (DRX) models:

- $\quad$ Yada model [17]

- Zener-Hollomon model [18]

- Dislocation density-based model [19]

- Johnson-Mehl-Avrami-Kolmogorov (JMAK) model [20]

- Helmholtz free energy model [21]

Ramesh and Melkote presented a Finite Element approach in Abaqus/Explicit for the modelling of White Layer formation based on the martensite phase transformation for orthogonal cutting of AISI 5200 in hardened state [8]. They showed that White Layer leads to a compressive residual stress on the rim zone.

In another study, Akcan et al. examined the microstructure and mechanical properties of the White Layer on machining of AISI 52100 steel cylinders which were hardened and tempered [9]. Analyzes of the machined surface showed a White Layer thickness of $8.2 \mu \mathrm{m}$ at $50 \mathrm{~m} / \mathrm{min}$ cutting speed, $0.2 \mathrm{~mm}$ depth of cut and $0.1 \mathrm{~mm} / \mathrm{rev}$ of feeding rate. An increase in the thickness of the White Layer was observed with the increasing cutting speed and flank wear.

For the hard machining of AISI 52100, Umbrello et al. [22] proposed a hardness-based flow rule, which is extended in [10] by advanced empirical models for phase transformation to simulate microstructural changes on Surface Integrity, such as White and Dark Layers with related changes in hardness. By considering the phase transformation, it was tacitly assumed that the austenitizing temperature would be exceeded during the process, which makes it difficult to implement this model for other materials. Caruso et al. applied the mentioned hardness-based flow stress and coupled it with the Zener-Hollomon model to predict the grain size [23]. They showed that the increase in cutting speed causes a thicker White Layer, while the thickness of the Dark Layer decreases with increasing cutting speed. In addition, a higher cutting speed leads to a Dark Layer dominated by grain refining. Caruso et al. also pointed out that the average grain size in the White Layer increases with 
increasing cutting speed [23]. The FEM software SFTC Deform ${ }^{\circledR}-2 \mathrm{D}$ with Updated Lagrangian method and re-meshing were utilized in their simulations.

In a separate study, Ambrosy et al. implemented the Zener-Hollomon approach in Abaqus/Implicit with user-defined continuous re-meshing algorithm to model nanocrystalline grains in orthogonal cutting of AISI 4140 steel [24]. They revealed that the grain refinement and thickness of DRX-layer increase with the increasing relative roundness $r_{\beta} / h$, which is the ratio of cutting edge radius $r_{\beta}$ to undeformed chip thickness $h$.

To simulate the effect of tool geometry and cutting conditions on microstructural alterations in turning of Ti-6Al-4V alloys, Arisoy and Özel used the JMAK model in SFTC Deform ${ }^{\circledR}{ }^{-}$-3D [25]. They showed that regarding to change of microhardness on the rim zone tool coating does not play a decisive role at low cutting speeds $\left(v_{c}=55 \mathrm{~m} / \mathrm{min}\right)$, while the TiAlN coated tool leads for the investigated process parameter to larger grains in contrast to uncoated tool. Furthermore, in their study, the grain size decreases with smaller cutting radius at low cutting speeds. Similarly, the average grain size decreases with increasing feed rate.

The study by Estrin et al. introduced a dislocation density-based model to describe strain hardening behavior [19], which is then employed in [26] to model grain refinement in equal channel angular pressing for copper. Ding et al. applied this dislocation density-based model for the simulation of dislocation density and grain size evolution of titanium in [27] and of A16061-T6 alloys in [28] after orthogonal cutting, respectively. This approach was later utilized by Atmani et al. [29] to simulate the grain refinement in machining of oxygen-free high conductivity copper. This DRX model has also been adapted for (hard) machining of steels latest by Li et al. for H13 steel [30] and earlier by Ding and Shin for AISI 52100 steel [31]. In these studies [26-30], the FE software Abaqus/Explicit with CEL along with ALE methods and in [31] AdvantEdge FEM were used.

Recently, Buchkremer and Klocke have presented a thermodynamically motivated DRX model based on the variation of Helmholtz free energy to predict the dynamically recrystallized grain size during the orthogonal cutting of AISI 4140 with SFTC Deform ${ }^{\circledR}-2 \mathrm{D}$ [21]. Their experimental and simulative results showed that the austenitizing temperature is not reached or exceeded for cutting speeds $v_{\mathcal{C}}=50-150 \mathrm{~m} / \mathrm{min}$ and undeformed chip thicknesses $h=0.05-0.2 \mathrm{~mm}$. Thus, a phase transformation is not expected for the White Layer formation, which is also proven by their X-ray diffraction. Moreover, the results of the finite element model showed a White Layer thickness of $2 \mu \mathrm{m}$ for $v_{c}=50 \mathrm{~m} / \mathrm{min}$ and $h=0.05 \mathrm{~mm}, 2.5 \mu \mathrm{m}$ for $v_{c}=150 \mathrm{~m} / \mathrm{min}$ and $h=0.05 \mathrm{~mm}, 1.8 \mu \mathrm{m}$ for $v_{c}=50 \mathrm{~m} / \mathrm{min}$ and $h=0.20 \mathrm{~mm}, 2.2 \mu \mathrm{m}$ for $v_{c}=150 \mathrm{~m} / \mathrm{min}$ and $h=0.20 \mathrm{~mm}$, which corresponds well to the presented experimental results. It can be deduced from these findings that the White Layer thickness increases with increasing cutting speed, while it decreases with increasing undeformed chip thickness.

Zhang and Zhuang analyzed the effect of cutting edge geometry on White Layer formation when cutting AISI 52100 steel [32]. Under the assumption that White Layer formation is related to rapid heating during the process, they implemented a phase transition temperature depending on stress, strain and current temperature to estimate the White Layer thickness with a hybrid approach. The 2D chip formation model was built up in Abaqus/Explicit using ALE method. They showed that White Layer thickness and process temperature increase with increasing cutting edge radius at constant cutting speed and undeformed chip thickness. This was also observed in experiments.

It can be concluded that machining-induced surface layer modifications are functions of thermo-mechanical process parameters and can be controlled or manipulated by skillful combinations. This paper focuses on FEM based modelling of White Layers in the hard machining of AISI 4140 steel, which can be used to determine the process parameters where the formation of White Layers is reduced or does not occur at all. The modelling results could be highly interesting from an industrial perspective as well. Since the FEM analyses are relatively time-consuming and cannot be used for monitoring a real process with respect to Surface Integrity, the accurate simulations can be utilized to calibrate a so-called Soft-Sensor, which is able to work with fast analytical empirical relations between 
the process forces and temperatures [33-35], in order to predict or avoid the possible formation of White Layers during the machining process. The calibrated Soft-Sensor could then be used to control the process and adjust related process parameters to increase the quality of machined parts [35]. This concept has not been well researched yet, but offers great potential.

Based on the research conducted by Buchkremer and Klocke, dynamic recrystallization is considered as a fundamental mechanism of the White Layer formation [21]. The above-mentioned empirical DRX models, Yada, Zener-Hollomon and JMAK, were very similar in terms of strain-based formulation of the DRX onset criteria (i.e., current plastic strain $\geq$ critical plastic strain) and recrystallized grain size calculation. Still, there are some differences. The main difference is that Yada model did not consider the recrystallized volume fraction as a function of time, while Zener-Hollomon and JMAK models took the DRX kinetics based on Arrhenius and Avrami type equations into account, respectively. In this work, the authors chose the Zener-Hollomon model among others because of its relatively simple implementation and calibration. It is also powerful enough to model White Layer formation due to DRX. In the case of the dislocation density-based model there are no specific DRX criteria and grain size refinement is calculated based on the total dislocation density which is given by a rule of mixtures. This approach will be analyzed in the upcoming work. Therefore, two different DRX models, Zener-Hollomon (empirical) and Helmholtz free energy (physics-based), were investigated and implemented in a Finite Element model and the results were compared and validated with different set of process parameters.

\section{Material}

In this work, the investigated material was a low alloyed quenched/tempered AISI 4140 steel, which is used for the manufacturing of steering knuckles, connecting rods, crankshafts, gear shafts or gear wheels in automotive and aircraft industries. Its chemical composition, mechanical and physical properties are given in Table 1.

Table 1. Chemical composition, mechanical and physical properties of quenched/tempered AISI 4140 [21].

\begin{tabular}{|c|c|c|c|}
\hline Property & Notation & Value & Unit \\
\hline \multirow{7}{*}{ Chemical composition } & $\mathrm{C}$ & 0.415 & mass- $\%$ \\
\hline & $\mathrm{Si}$ & 0.40 & mass- $\%$ \\
\hline & $\mathrm{Mn}$ & 0.75 & mass-\% \\
\hline & $\mathrm{Cr}$ & 1.05 & mass- $\%$ \\
\hline & Mo & 0.225 & mass- $\%$ \\
\hline & $\mathrm{S}$ & 0.3 & mass-\% \\
\hline & $\mathrm{Fe}$ & 97.13 & mass- $\%$ \\
\hline Young's modulus & $E$ & 204,223 & $\mathrm{MPa}$ \\
\hline Poisson ratio & $v$ & 0.3 & {$[-]$} \\
\hline Mass density & $\rho$ & $7.619 \times 10^{-9}$ & ton $/ \mathrm{mm}^{3}$ \\
\hline \multirow{2}{*}{ Heat capacity } & $c_{p}(T \leq 1073 \mathrm{~K})$ & $200 \cdot T^{2}-65.4 \times 10^{3} \cdot T+477.04 \times 10^{6}$ & $\mathrm{~mJ} /$ ton $/ \mathrm{K}$ \\
\hline & $c_{p}(T>1073 \mathrm{~K})$ & $-24.9 \times 10^{3} \cdot T-723.86 \times 10^{6}$ & $\mathrm{~mJ} /$ ton $/ \mathrm{K}$ \\
\hline Thermal conductivity & $k$ & 42.6 & $\mathrm{~mW} / \mathrm{mm} / \mathrm{K}$ \\
\hline Hardness & $H V$ & 48 & HRC \\
\hline Initial grain size & $d_{0}$ & 680 & $\mathrm{~nm}$ \\
\hline
\end{tabular}

\section{Finite Element Method-Based Modelling of Hard Machining}

Hard machining is a complicated process to model due to the high temperatures, strain rates and extensive plastic deformations. The main problem hereby is the distorted elements during chip formation. There are several techniques to handle this problem in FE simulations, some of them are listed below considering the FEM software Abaqus.

- $\quad$ Element deletion (explicit) 
- Coupled-Eulerian-Lagrangian (CEL) method (explicit)

- $\quad$ Re-meshing with Updated Lagrangian (UL) method (implicit)

In modelling of DRX on the rim zone temperature is one of the relevant state variables. Since element deletion does not involve temperature transfer from the deleted element to the element under it, this method is not suitable for the DRX modelling. Not to mention that due to element deletion, the machined surface layer is lost. In the CEL and UL methods there is a continuous contact between the elements themselves and the cutting tool, which makes them suitable for the calculation of dynamically recrystallized grain size on the workpiece surface. Due to the fact that the implemented re-meshing algorithm in Abaqus is not good enough to model the machining process, this paper focuses on the CEL approach.

\section{Modelling with CEL Method in Abaqus/Explicit}

A 3D model with a thickness of one element $(2 \mu \mathrm{m})$ based on the CEL approach for orthogonal cutting was developed in Abaqus/Explicit 2018, as shown in Figure 1. In this approach, the Euler space has to be specified in terms of material (workpiece) and void to ensure that the removal chip flows out into the void. For a better contact behavior, the tool (rigid) should be placed in the Euler space. Besides, a plate (rigid), made of the same material as the tool, was placed over the workpiece in Euler space, to prevent the rolling chip from touching the surface of the workpiece. This method is called Coupled-Euler-Lagrangian, because tool and workpiece were meshed according to Lagrangian and Euler approaches, respectively. The Euler mesh is fixed in space and the material moves through it, while the nodes of an element in Lagrangian mesh move with the material and a mesh deformation takes place. For meshing of the workpiece and void the element type EC3D8RT was used, which stands for thermally coupled linear brick elements with eight nodes and one Gauß point.

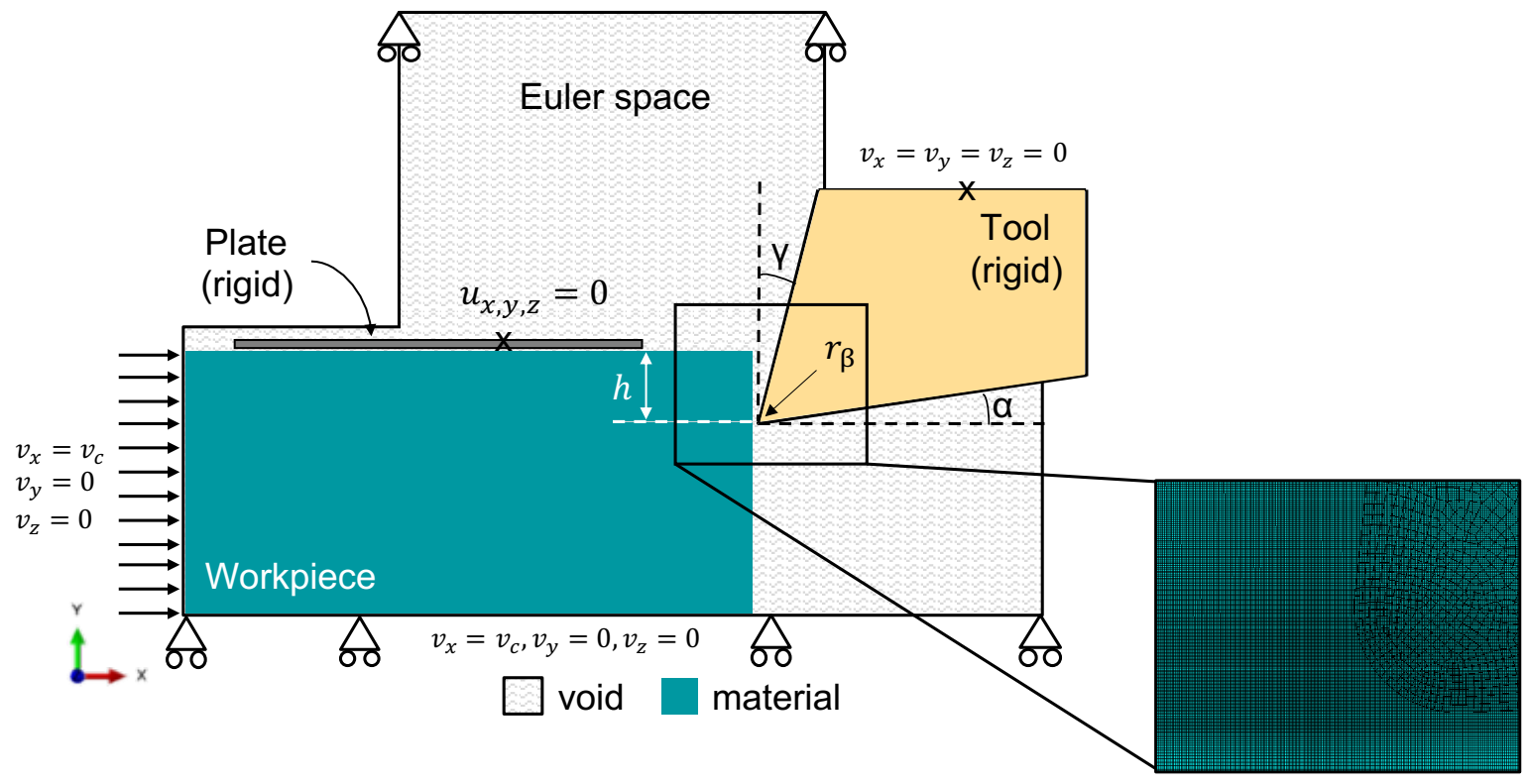

Figure 1. Orthogonal cutting model with the Coupled-Eulerian-Lagrangian method in Abaqus/Explicit.

The tool and plate were meshed by utilizing the element type C3D8T, which describes an eight-node trilinear displacement and temperature element with eight Gauß points. Tool geometry and cutting parameters used in the simulations and experiments are listed in Table 2.

To represent the DRX on the surface layer and the resulting chip geometry in Euler space successfully, the mesh size must be fine enough. For this reason, the mesh size of the workpiece in this model was set to $0.9 \mu \mathrm{m}$, while the mesh size of the tool on the cutting radius was $4 \mu \mathrm{m}$. For the modelling of DRX in orthogonal cutting, a full coupled thermo-mechanical analysis step was employed. 
The boundary conditions in Euler space were formulated in terms of velocity, where the material flow in $\mathrm{z}$-direction was prohibited in the whole model, while the material flow in y-direction was allowed for chip formation. The tool and plate were fixed in terms of velocity and displacement boundary conditions, respectively. Only workpiece moves with a prescribed cutting velocity $v_{c}$ against the tool.

Friction has a great influence on the simulation results in terms of temperature. In this work, Coulomb friction coefficient was formulated as a function of cutting speed $v_{c}$. Figure 2 shows the measured Coulomb friction coefficient at different cutting speeds [21] and their linear interpolation, which is implemented into Abaqus.

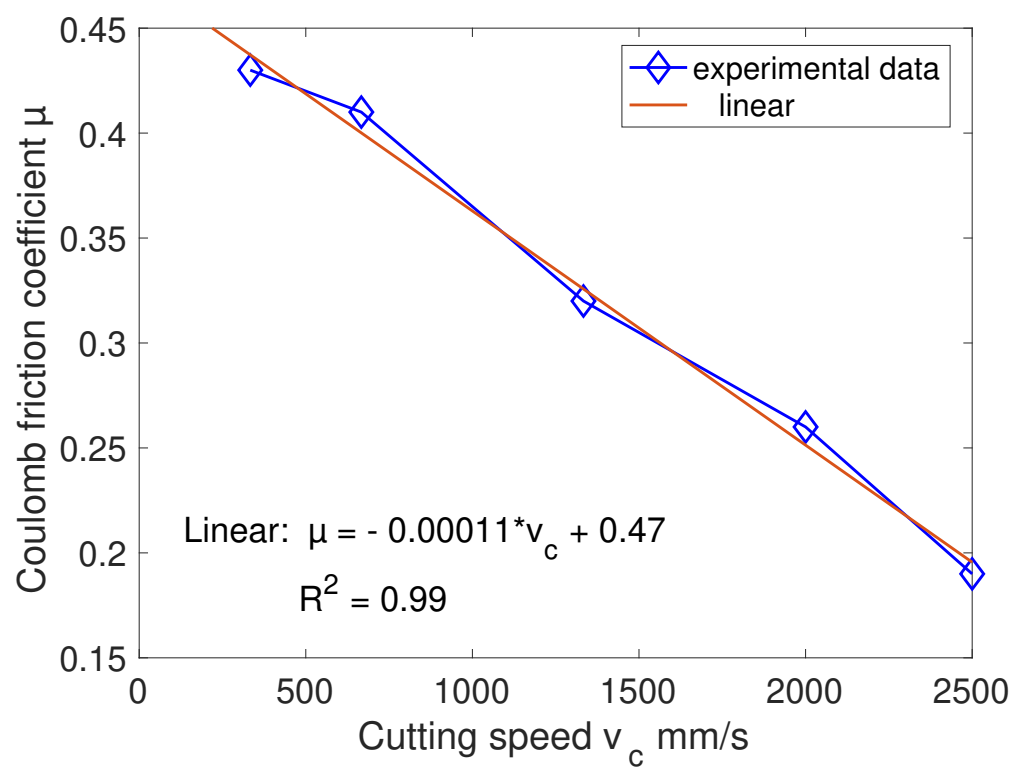

Figure 2. Description of Coulomb friction coefficient as a function of cutting speed based on [21].

Since the CEL simulations were time consuming, it was necessary to implement a mass scaling to increase the explicit time step so that the computing time could be reduced. The modelling related material parameters of workpiece and tool are depicted in Tables 1 and 3, respectively. Note that the utilized mass scaling factor of $10^{4}$ was not taken into account when specifying the properties, such as density and heat capacity.

Table 2. Tool geometry and cutting parameters used in the simulations and experiments [36].

\begin{tabular}{lccc}
\hline Property & Notation & Value & Unit \\
\hline Clearance/Flank angle & $\alpha$ & 3 & $\circ$ \\
Rake angle & $\gamma$ & 6 & $\circ$ \\
Cutting edge radius & $r_{\beta}$ & $66 \pm 2.7$ & $\mu \mathrm{m}$ \\
Flank wear & $V B_{\max }$ & 20 & $\mu \mathrm{m}$ \\
Cutting speed & $v_{c}$ & $50,100,150$ & $\mathrm{~m} / \mathrm{min}$ \\
Undeformed chip thickness & $h$ & $0.05,0.1,0.2$ & $\mathrm{~mm}$ \\
\hline
\end{tabular}

Table 3. Mechanical and physical properties of cutting tool (Sandvik H13A) [21].

\begin{tabular}{lccc}
\hline Property & Notation & Value & Unit \\
\hline Young's modulus & $E$ & 600,000 & $\mathrm{MPa}$ \\
Poisson ratio & $v$ & 0.22 & {$[-]$} \\
Mass density & $\rho$ & $1.5 \times 10^{-9}$ & ton $/ \mathrm{mm}^{3}$ \\
Heat capacity & $\bar{c}_{p}$ & $250 \times 10^{6 *}$ & $\mathrm{~mJ} / \mathrm{ton} / \mathrm{K}$ \\
Thermal conductivity & $\bar{k}$ & $66.3^{*}$ & $\mathrm{~mW} / \mathrm{mm} / \mathrm{K}$ \\
\hline \multicolumn{4}{c}{ average value. }
\end{tabular}




\section{Modelling of Dynamic Recrystallization}

In this section, the material model and two different approaches to modelling dynamic recrystallization are introduced briefly.

\subsection{Material Model}

The visco-plastic material behavior of AISI 4140 was described based on the phenomenological constitutive material model of Johnson-Cook (JC) [37]. The yield potential $\bar{\sigma}_{Y}$ is given as a function of temperature, strain rate and plastic strain in Equation (1). The influence of stress state (stress triaxiality \& Lode angle) and damage are not considered in this formulation. Furthermore, the strengthening mechanism through dislocation damping at high strain rates $(>5001 / \mathrm{s})$ is also not taken into account.

$$
\begin{gathered}
\bar{\sigma}_{Y}\left(\overline{\bar{\varepsilon}}^{p}, \dot{\bar{\varepsilon}}^{p}, T\right)=\left[A+B \cdot\left(\bar{\varepsilon}^{p}\right)^{n}\right] \cdot\left[1+C \cdot \ln \left(\frac{\dot{\bar{\varepsilon}}^{p}}{\overline{\bar{\varepsilon}}_{0}^{p}}\right)\right] \cdot\left[1-(\hat{T})^{m}\right] \\
\text { with } \hat{T}=\left\{\begin{array}{lll}
0 & \text { for } T<T_{0} \\
\frac{T-T_{0}}{T_{m}-T_{0}} & \text { for } \quad T_{0}<T_{m} \\
1 & \text { for } \quad T>T_{m}
\end{array}\right.
\end{gathered}
$$

where $A$ is the yield stress at reference temperature $T_{0}$ and strain rate $\dot{\bar{\varepsilon}}_{0}^{p}, B$ stands for the strain hardening coefficient, $n$ denotes the exponent of strain hardening, $C$ and $m$ are the material constants that represent the coefficient of strain rate hardening and the thermal softening exponent, respectively. While $T_{m}$ refers the melting temperature, $T$ represents the current temperature. The calibrated model parameters for the material AISI 4140 were taken from Buchkremer and Klocke [21] and listed in Table 4.

Table 4. Johnson-Cook model parameters of AISI 4140 [21].

\begin{tabular}{lccc}
\hline Property & Notation & Value & Unit \\
\hline Initial yield stress & $A$ & 1450 & $\mathrm{MPa}$ \\
Hardening modulus & $B$ & 910 & $\mathrm{MPa}$ \\
Work-hardening exponent & $n$ & 0.45 & {$[-]$} \\
Strain rate dependency coefficient & $C$ & 0.034 & {$[-]$} \\
Thermal softening coefficient & $m$ & 0.328 & {$[-]$} \\
Room temperature & $T_{0}$ & 293.15 & $\mathrm{~K}$ \\
Melting temperature & $T_{m}$ & 1809.15 & $\mathrm{~K}$ \\
Reference strain rate & $\dot{\varepsilon}_{0}$ & 0.001 & $1 / \mathrm{s}$ \\
\hline
\end{tabular}

VUHARD subroutine was employed for coding Johnson-Cook model in Abaqus/Explicit, because this subroutine allows to call the values of the state variables from previous $t-1$ and current $t$ time steps, which are needed later when implementing the DRX models. VUHARD subroutine requires the given partial derivatives of the yield potential in Equations (2)-(4) as output to calculate the hardening behavior. Note that, the temperature was calculated by Abaqus during the explicit dynamic temperature-displacement coupled analysis.

$$
\frac{\partial \bar{\sigma}_{Y}}{\partial \bar{\varepsilon}^{p}}= \begin{cases}0 & \text { for } \quad \bar{\varepsilon}^{p} \leq 0 \\ {\left[n \cdot B \cdot\left(\bar{\varepsilon}^{p}\right)^{n-1}\right] \cdot\left[1+C \cdot \ln \left(\frac{\dot{\bar{\varepsilon}}^{p}}{\overline{\bar{\varepsilon}}_{0}^{p}}\right)\right] \cdot\left[1-(\hat{T})^{m}\right]} & \text { for } \quad \text { else }\end{cases}
$$




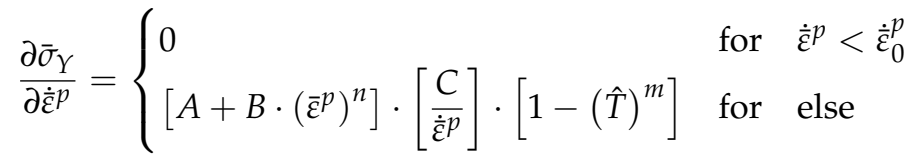

$$
\begin{aligned}
& \frac{\partial \bar{\sigma}_{Y}}{\partial T}= \begin{cases}{\left[A+B \cdot\left(\bar{\varepsilon}^{p}\right)^{n}\right] \cdot\left[1+C \cdot \ln \left(\frac{\dot{\bar{\varepsilon}}^{p}}{\overline{\bar{\varepsilon}}_{0}^{p}}\right)\right] \cdot\left[-m \cdot \frac{1}{T_{m}-T_{0}} \cdot(\hat{T})^{m-1}\right]} & \text { for } 0<\hat{T}<1 \\
0 & \text { for else }\end{cases}
\end{aligned}
$$

\subsection{Zener-Hollomon Model}

Zener-Hollomon model is an empirical model for the prediction of dynamically recrystallized grain size. A detailed review of this model is given in literature $[18,24]$. Briefly, the Zener-Hollomon parameter $Z_{H}$ gives the relation between the working temperature and the equivalent plastic strain rate, which can be calibrated by performing compression tests at different temperatures and strain rates.

$$
Z_{H}=\dot{\bar{\varepsilon}}^{p} \cdot \exp \left[\frac{Q}{R \cdot T}\right]
$$

where $\dot{\bar{\varepsilon}}^{p}$ denotes the equivalent plastic strain rate, $Q$ in $\mathrm{J}$ stands for the activation energy, $R$ in $\mathrm{J} / \mathrm{mol} / \mathrm{K}$ is the universal gas constant and $T$ in $\mathrm{K}$ represents the current temperature. The dynamically recrystallized grain size $d_{\mathrm{DRX}}$ in $\mu \mathrm{m}$ can be calculated according to $[18,24]$ as follows,

$$
d_{\mathrm{DRX}}=\underbrace{\kappa_{0} \cdot d_{0}}_{\kappa_{1}} \cdot Z_{H}^{-\kappa_{2}}
$$

where $\kappa_{i}$ represent the material related constants. According to this model, a critical plastic strain $\bar{\varepsilon}_{\text {crit }}^{p}$ depending on the Zener-Hollomon $Z_{H}$ parameter and grain size from previous time step $d_{t-1}$ has to be determined, as shown in Equation (7) [18].

$$
\bar{\varepsilon}_{c r i t}^{p}=\kappa_{3} \cdot \sqrt{d_{t-1}} \cdot Z_{H}^{\kappa_{4}}
$$

In this model, the driving force for the DRX initiation is the equivalent plastic strain $\bar{\varepsilon}^{p}$, so dynamic recrystallization takes place when the current plastic strain reaches or exceeds the critical one. Note that, the same criterion has been adopted for the initiation of White Layer formation. The DRX kinetics model in incremental form represented in Equation (8) and based on the Avrami function, is used to determine the recrystallized volume fraction triggered by the plastic strain [18]. To update the volume fraction, Forward Euler (explicit) integration scheme can be used, which is given in Equation (9).

$$
\begin{gathered}
\mathrm{d} X^{\mathrm{DRX}}=J \cdot \kappa_{5} \cdot\left(\bar{\varepsilon}^{p}-\bar{\varepsilon}_{c r i t}^{p}\right)^{\kappa_{5}-1} \cdot \exp \left[-J \cdot\left(\bar{\varepsilon}^{p}-\bar{\varepsilon}_{c r i t}^{p}\right)^{\kappa_{5}}\right] \cdot \mathrm{d} \bar{\varepsilon}^{p} . \\
X_{t}^{\mathrm{DRX}}=X_{t-1}^{\mathrm{DRX}}+\mathrm{d} X^{\mathrm{DRX}} .
\end{gathered}
$$

In the equation, $X^{\mathrm{DRX}}$ and $\mathrm{d} X^{\mathrm{DRX}}$ describe the volume fraction and its increment, respectively. While $t$ represents the current time step, $t-1$ is the previous time step. $J$ is defined as the rate of dynamic recrystallization and depends on the strain $\bar{\varepsilon}_{50 \%}$ at $50 \%$ DRX.

$$
J=\frac{\kappa_{6}}{\bar{\varepsilon}_{50 \%}^{\kappa_{5}}}=\frac{\kappa_{6}}{\kappa_{7} \cdot\left(\kappa_{8} \cdot \sqrt{d_{t-1}} \cdot Z_{H}^{\kappa_{9}}-\bar{\varepsilon}_{c r i t}^{p}\right)^{\kappa_{5}}}
$$


Average grain size $d_{t}$ in $\mu \mathrm{m}$ is composed of recrystallized $d_{\mathrm{DRX}}$ and non-recrystallized $d_{t-1}$ grains, as shown in Equation (11).

$$
d_{t}=\left[1-X_{t}^{\mathrm{DRX}}\right] \cdot d_{t-1}+d_{\mathrm{DRX}} \cdot X_{t}^{\mathrm{DRX}}
$$

Based on the Hall-Petch relation the change in hardness can be calculated using current grain size according to the following equation, where $\kappa_{H P}$ is a material parameter and $H V_{0}$ in $\mathrm{HV}$ is the initial hardness [38].

$$
H V_{t}=H V_{0}+\frac{\kappa_{H P}}{\sqrt{d_{t}}}
$$

The material parameters were iteratively fitted using a Python script developed by Mr. Alexander Schowtjak at IUL/TU-Dortmund. The parameters from Ambrosy et al. [24] were used as initial guess, because these parameters showed a very good agreement for the investigated material AISI 4140 with $d_{0}=10 \mu \mathrm{m}$ in their work. Yet, it was not possible to minimize the objective function with those values as initial guess. Therefore, this model was additionally implemented into MATLAB to optimize the initial guess based on an element on the workpiece rim zone.

The calibrated parameters at the cutting condition $v_{\mathcal{c}}=150 \mathrm{~m} / \mathrm{min}$ and $h=0.05 \mathrm{~mm}$ are summarized in Table 5 .

\begin{tabular}{|c|c|c|c|}
\hline Property & Notation & Value & Unit \\
\hline Activation energy & $Q$ & 394,000 & $\mathrm{~J} / \mathrm{mol} / \mathrm{K}$ \\
\hline Universal gas constant & $\widetilde{R}$ & 8.3145 & $\mathrm{~J} / \mathrm{mol}$ \\
\hline Initial grain size & $d_{0}$ & 0.68 & $\mu \mathrm{m}$ \\
\hline \multirow{10}{*}{ Fitting parameters } & $\kappa_{0}$ & 85,715 & {$[-]$} \\
\hline & $\kappa_{1}$ & 58,286 & {$[-]$} \\
\hline & $\kappa_{2}$ & 0.222146011 & {$[-]$} \\
\hline & $\kappa_{3}$ & 0.010329236 & {$[-]$} \\
\hline & $\kappa_{4}$ & 0.10456389 & {$[-]$} \\
\hline & $\kappa_{5}$ & 2.347035604 & {$[-]$} \\
\hline & $\kappa_{6}$ & 0.776424878 & {$[-]$} \\
\hline & $\kappa_{7}$ & 1.06946987 & {$[-]$} \\
\hline & $\kappa_{8}$ & 0.000562152 & {$[-]$} \\
\hline & $\kappa_{9}$ & 0.152615136 & {$[-]$} \\
\hline \multirow{2}{*}{ Hall-Petch parameters [39] } & $H V_{0}$ & 417 & $\mathrm{HV}$ \\
\hline & $\kappa_{H P}$ & 18.009 & $\mathrm{MPa} / \sqrt{\mathrm{mm}}$ \\
\hline
\end{tabular}

Table 5. Zener-Hollomon and Hall-Petch parameters of AISI 4140.

The Zener-Hollomon model was implemented into the commercial software Abaqus/Explicit utilizing the user-defined subroutine VUHARD which was programmed in FORTRAN. The corresponding algorithm is given in Algorithm 1. 


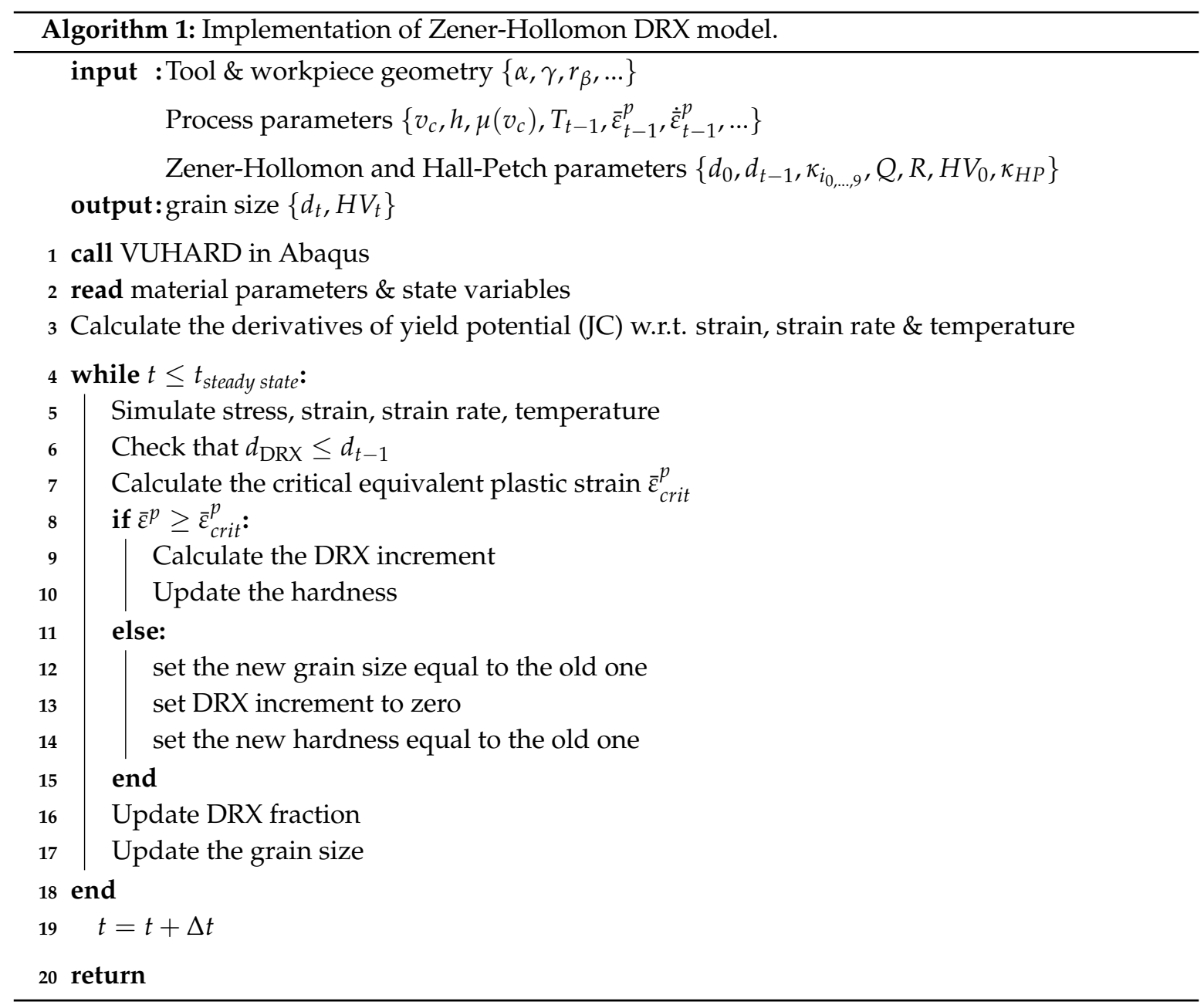

\subsection{Helmholtz Free Energy Model}

In this section, the Helmholtz free energy model is introduced. A full derivation of this approach can be found in the research of Buchkremer and Klocke [21]. This framework for DRX is thermodynamically driven and based on the variation of Helmholtz free energy $\mathrm{d} \psi$.

$$
\mathrm{d} \psi=\mathrm{d} u-\mathrm{d} \cdot[s \cdot T]=\mathrm{d} u-[s \cdot \mathrm{d} T+T \cdot \mathrm{d} s],
$$

where $u$ and $s$ represent the specific internal energy and specific entropy, respectively. T stands for the temperature. The variation in specific internal energy $\mathrm{d} u$ can be calculated as sum of the variation in mechanical $\mathrm{d} e_{M}$, thermal $\mathrm{d} e_{T}$ and interface energy $\mathrm{d} e_{I}$.

$$
\mathrm{d} u=\mathrm{d} e_{M}+\mathrm{d} e_{T}+\mathrm{d} e_{I}
$$

The variation of mechanical energy $\mathrm{d} e_{M}$ is given by the integration of the yield potential (here, of JC) with respect to equivalent plastic strain $\bar{\varepsilon}^{p}$, as presented in Equation (15).

$$
\mathrm{d} e_{M}=\int_{\bar{\varepsilon}_{t-1}^{p}}^{\bar{\varepsilon}_{t}^{p}} \bar{\sigma}_{Y}\left(\bar{\varepsilon}^{p}, \dot{\bar{\varepsilon}}^{p}, T\right) \cdot \mathrm{d} \bar{\varepsilon}^{p}
$$


The driving force here is the stored dislocation energy, which is equal to the undissipated part of the specific mechanical energy $\left(=0.1 \cdot \mathrm{d} e_{M}\right)$ [21]. The onset of DRX is characterized by the following three conditions:

1. Critical temperature must be exceeded: $T \geq T_{\text {crit }} \quad$ with $\quad T_{\text {crit }}=0.4 \cdot T_{m}$ in ${ }^{\circ} \mathrm{C}$

2. Critical specific mechanical energy must be exceeded: $0.1 \cdot \mathrm{d} e_{M} \geq e_{M_{\text {crit }}}$

3. Variation of the Helmholtz free energy should be negative: $\mathrm{d} \psi<0$

All these three criteria must be fulfilled for grain size evolution due to dynamic recrystallization according to current model. The physical meaning of the 3rd criterion is that grain refinement takes place spontaneously, when Helmholtz free energy decreases [21]. Since the DRX is the fundamental mechanism for the formation of White Layers, same three criteria were interpreted from above as White Layer initiation conditions.

The new grain size $d_{t}$ in mm after DRX can be calculated as follows:

$$
d_{t}=\frac{3 \cdot e_{g b}(T)}{\frac{3 \cdot e_{g b}(T)}{d_{t-1}}+\lambda(T) \cdot 0.1 \cdot \mathrm{d} e_{M}}
$$

where $e_{g b}(T)$ denotes the grain boundary energy and $\lambda(T)$ represents the part of energy, which is transformed from stored dislocation energy into interface energy [21].

Grain refinement due to DRX has also an influence on the current plastic strain $\bar{\varepsilon}_{t}^{p}$ which can be considered according to Equation (17) based on the Johnson-Cook material model (see Equation (1)) [21].

$$
\begin{aligned}
& \bar{\varepsilon}_{t}^{p}=-\frac{A \cdot(n+1)}{2 \cdot B}+ \\
& \sqrt{\left[\frac{A \cdot(n+1)}{2 \cdot B}\right]^{2}+\frac{(n+1) \cdot 0.1 \cdot \mathrm{d} e_{M}}{\left[1+C \cdot \ln \left(\frac{\dot{\bar{\varepsilon}}^{p}}{\dot{\bar{\varepsilon}}_{0}^{p}}\right)\right] \cdot\left[1-(\hat{T})^{m}\right] \cdot B}}
\end{aligned}
$$

The calibrated model parameters are given in Table 6.

Table 6. Helmholtz free energy model parameters of AISI 4140 based on [21].

\begin{tabular}{lccc}
\hline Property & Notation & Value & Unit \\
\hline Grain boundary energy & $e_{g b}(T)$ & $-4.72 \times 10^{-7} \cdot \mathrm{T}+4.098 \times 10^{-3}$ & $\mathrm{~mJ} / \mathrm{mm}^{2}$ \\
Fraction of interface energy & $\lambda(T)$ & $1.667 \cdot \frac{T}{T_{m}}-0.667$ & {$[-]$} \\
Critical specific mechanical energy & $e_{M_{\text {crit }}}$ & 582 & $\mathrm{MPa}$ \\
Critical temperature & $T_{\text {crit }}$ & 887.55 & $\mathrm{~K}$ \\
Initial grain size & $d_{0}$ & $680 \times 10^{-6}$ & $\mathrm{~mm}$ \\
\hline
\end{tabular}

The Helmholtz free energy model was implemented using FORTRAN in user-defined subroutine VUHARD in Abaqus/Explicit according to the Algorithm 2. 


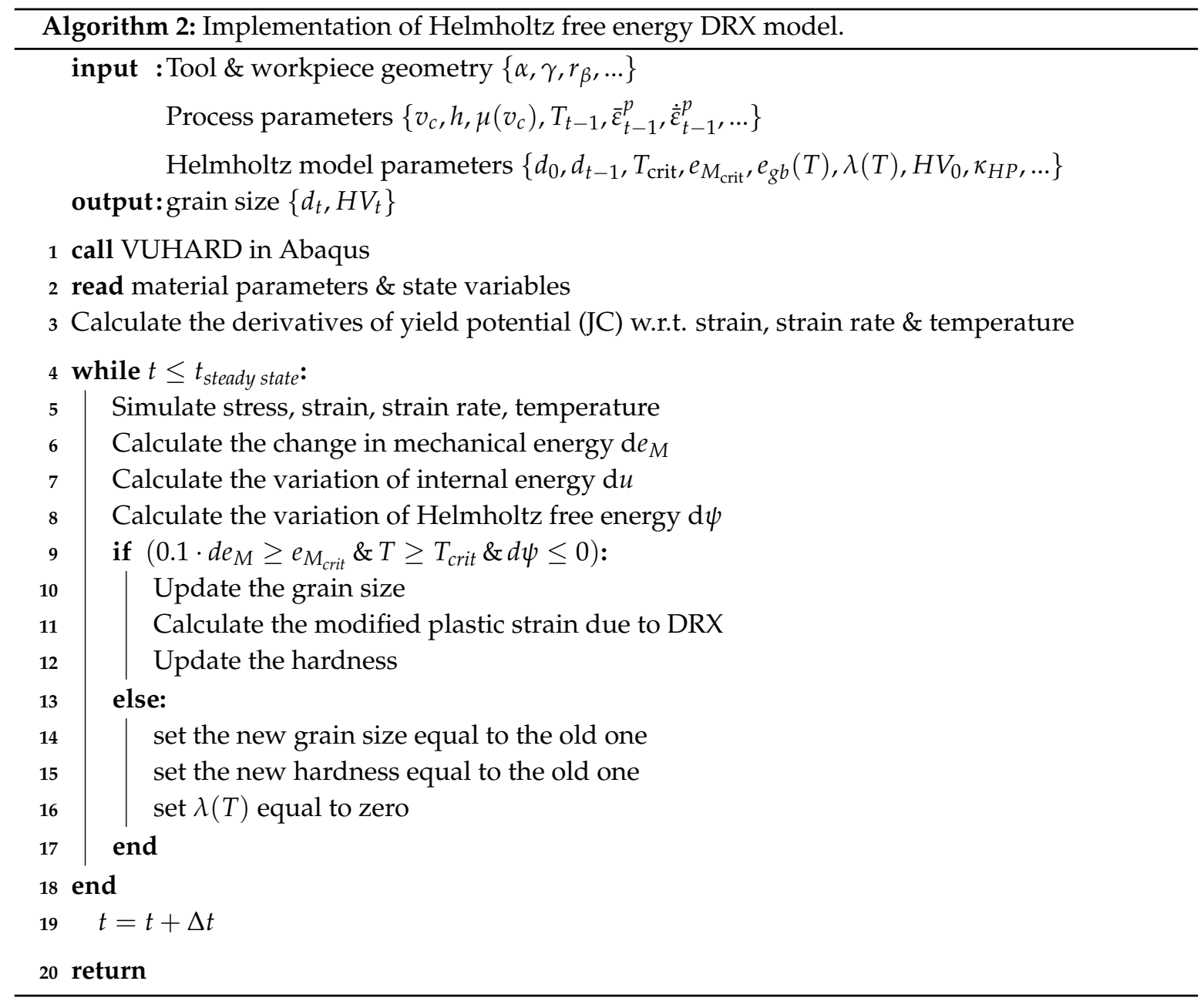

\section{Results and Discussion}

In this section, first, the validation of the introduced Finite Element orthogonal cutting model with respect to experimentally measured process forces at different cutting conditions is presented. Next, the predictions of the grain size refinement on the workpiece rim zone with Zener-Hollomon and Helmholtz free energy models are shown and finally, these results are compared and validated through experiments.

\subsection{Experimental Validation of the Finite Element Orthogonal Cutting Model}

To validate the FEM model, orthogonal cutting experiments at different cutting speeds $v_{\mathcal{c}}=50,100$ and $150 \mathrm{~m} / \mathrm{min}$ and undeformed chip thicknesses $h=0.05,0.1$ and $0.2 \mathrm{~mm}$ with a constant cutting tool geometry $\left(\alpha=3^{\circ}, \gamma=6^{\circ}\right.$ and $\left.r_{\beta}=66 \mu \mathrm{m}\right)$ were performed.

Figure 3a summarizes all predicted and experimentally measured and averaged cutting $F_{c}$ and feed forces $F_{f}$, which were taken from a steady state condition and normalized by the thickness $\delta$ of the workpiece $\left(\delta_{\text {sample }}=3.3 \mathrm{~mm}\right.$ and $\left.\delta_{\mathrm{CEL}}=2 \mu \mathrm{m}\right)$. Figure $3 \mathrm{~b}, \mathrm{c}$ exemplary show the evolution of the force components from experiment and simulation with a cutting speed of $v_{c}=50 \mathrm{~m} / \mathrm{min}$ and an undeformed chip thickness of $h=0.2 \mathrm{~mm}$. It can be seen from Figure 3a, on the one hand, the feed forces $F_{f}$ were generally underestimated with the CEL approach besides the cutting condition with $v_{c}=150 \mathrm{~m} / \mathrm{min}$ and $h=0.2 \mathrm{~mm}$. On the other hand, the cutting forces $F_{c}$ which were depending on the cutting condition either slightly overestimated or underestimated showed a better correlation with the experiments (except $v_{c}=150 \mathrm{~m} / \mathrm{min}$ and $h=0.2 \mathrm{~mm}$ ). The maximum deviations in cutting and feed forces were observed at a cutting depth of $h=0.2 \mathrm{~mm}$ and were $(+) 17 \%$ and $(-) 41 \%$ 
respectively. The general difference between CEL method and experiment in case of the feed forces has been also noted in literature $[40,41]$. As a possible explanation for this finding, the rapid deformation of the cutting edge in experiments based on the research [42,43] was given. Another reason could be the modeled length of the workpiece, which has an influence on the stress state and thus on the process forces in the CEL formulation.

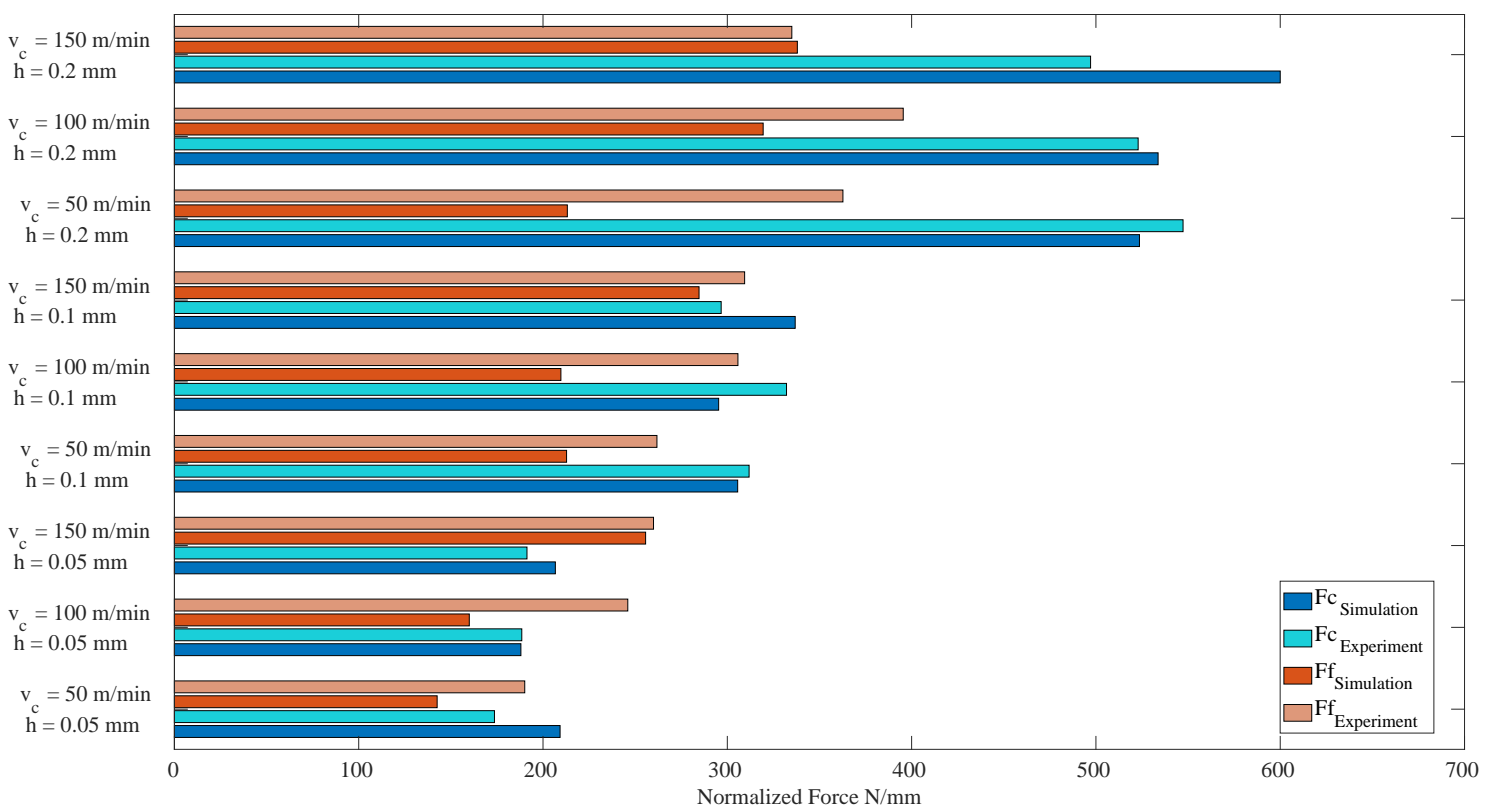

(a)

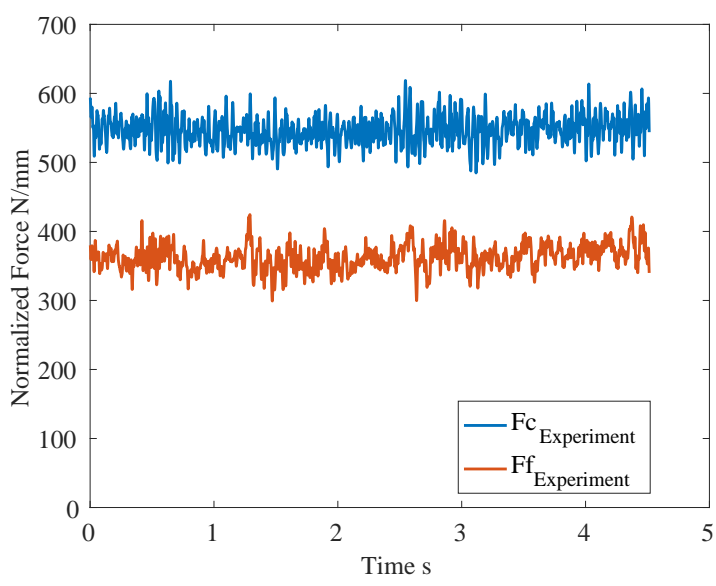

(b)

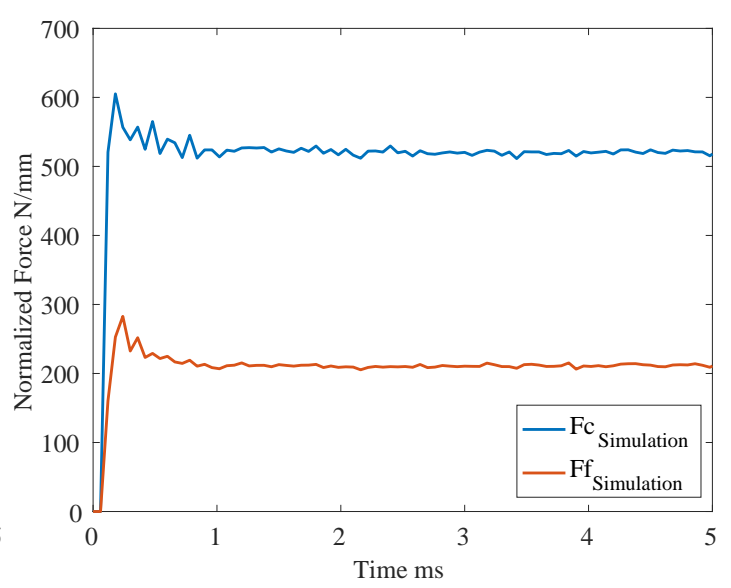

(c)

Figure 3. Normalized cutting forces $F_{c}$ and feed forces $F_{f}$ from simulation and experiment. (a) Comparison of the simulated and experimentally measured cutting force components at different cutting speeds and undeformed chip thicknesses; (b) Experimental force measurements under the cutting condition $v_{c}=50 \mathrm{~m} / \mathrm{min}$ and $h=0.2 \mathrm{~mm}$; (c) Cutting force components from CEL model under the cutting condition $v_{\mathcal{c}}=50 \mathrm{~m} / \mathrm{min}$ and $h=0.2 \mathrm{~mm}$.

\subsection{Prediction of the White Layer Thickness Using Helmholtz Free Energy and Zener-Hollomon Models}

For the validation of the Zener-Hollomon and Helmholtz free energy models the case studies from Table 7 were performed. 
Table 7. Hard turning experimental conditions for DRX-model verification [39].

\begin{tabular}{ccc}
\hline Cases for DRX & Cutting Velocity $\boldsymbol{v}_{\boldsymbol{c}}[\mathrm{m} / \mathbf{m i n}]$ & Undeformed Chip Thickness $\boldsymbol{h}$ [mm] \\
\hline 1 & 50 & 0.05 \\
2 & 150 & 0.05 \\
3 & 50 & 0.2 \\
4 & 150 & 0.2 \\
\hline
\end{tabular}

The grain size $d_{t}[\mathrm{~nm}]$ from the simulations within surface layer after dynamic recrystallization at undeformed chip thicknesses $h$ of $0.05 \mathrm{~mm}$ and $0.2 \mathrm{~mm}$ for cutting speeds $v_{c}=50$ and $150 \mathrm{~m} / \mathrm{min}$ are presented using the Helmholtz free energy and Zener-Hollomon models in Figures 4 and 5. The cutting edge radius $\gamma_{\beta}=66 \mu \mathrm{m}$, rake angle $\gamma=6^{\circ}$ and flank angle $\alpha=3^{\circ}$ were kept constant.

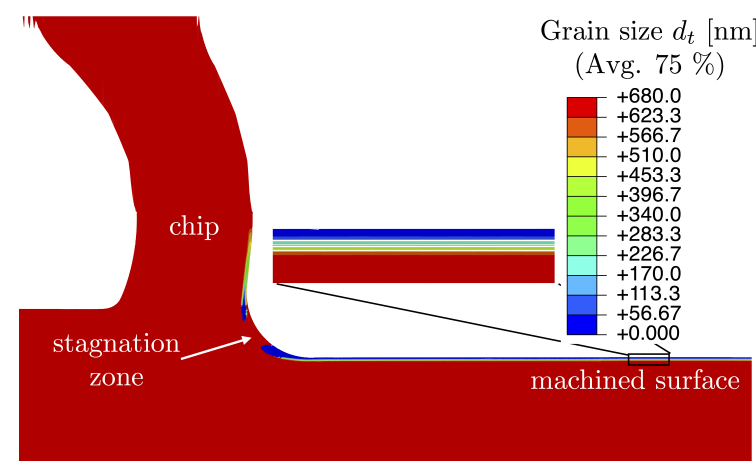

(a) Case 1: Helmholtz free energy model.

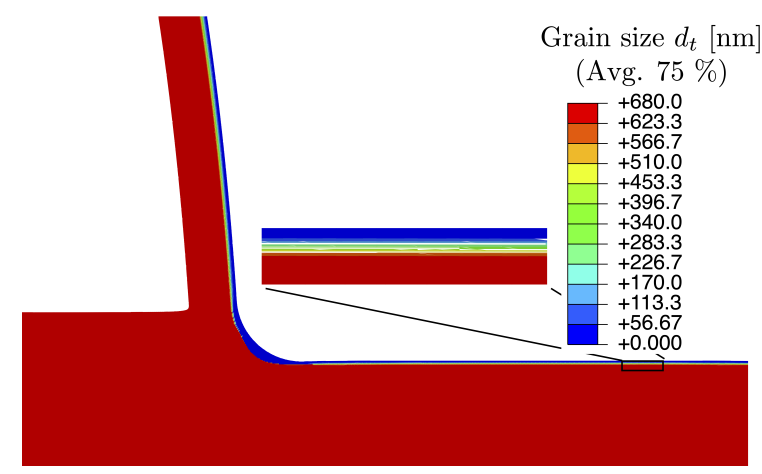

(c) Case 2: Helmholtz free energy model.

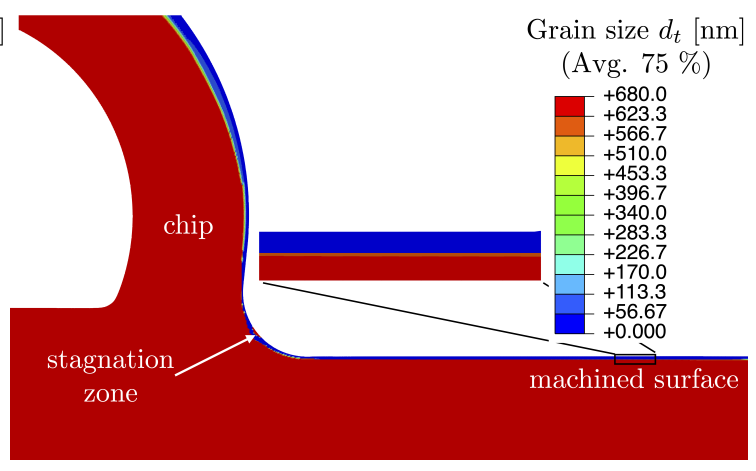

(b) Case 1: Zener-Hollomon model.

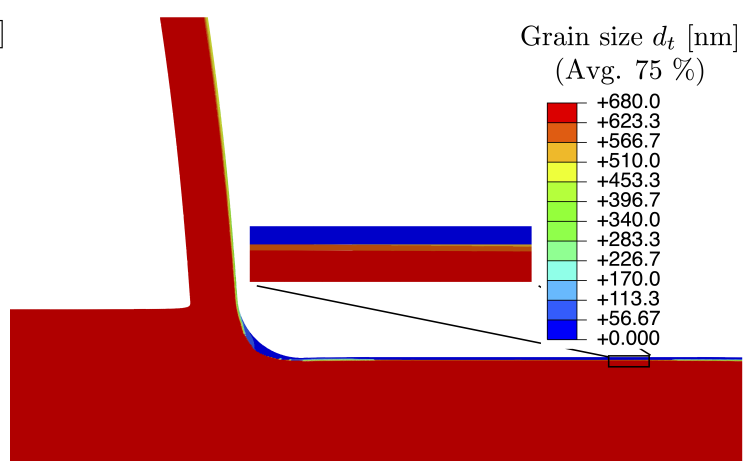

(d) Case 2: Zener-Hollomon model.

Figure 4. Prediction of grain size $d_{t}$ via Helmholtz energy and Zener-Hollomon models at investigated cases 1 and 2.

It can be seen, on the one hand, that at lower cutting speed $v_{c}=50 \mathrm{~m} / \mathrm{min}$ there was a distinct difference between the two DRX models regarding to the calculated recrystallized grain volumes at the chip surface (Figure $4 a, b$ ) but the prediction of DRX on the chip surface is not an interest of this study. On the other hand, both models predicted at lower cutting speed independent of the undeformed chip thickness a stagnation zone in front of the cutting edge radius where no DRX occurred (Figures $4 \mathrm{a}, \mathrm{b}$ and $5 \mathrm{a}, \mathrm{b}$ ). The stagnation zone is characterized by a lower relative velocity and also observed by Buchkremer and Klocke in their simulations $[39,44]$. Moreover, Figure 4 shows that at lower cutting depth $h=0.05 \mathrm{~mm}$ the Zener-Hollomon model could not predict the grain size evolution as accurate as Helmholtz free energy model and underestimates the grain size which can be recognized by the displayed color transitions blue(fine grains)-green-red(initial grain size) on the machined surface. In summary, as expected, both DRX models achieved similar results. 


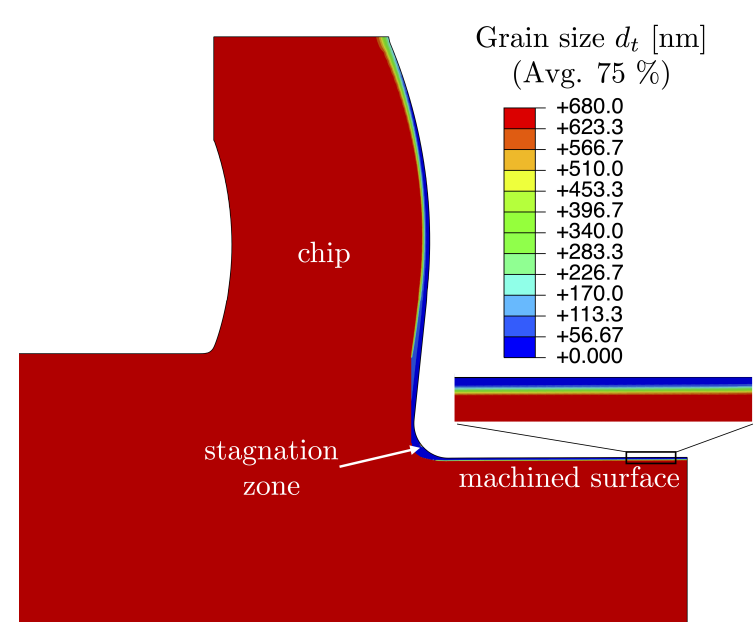

(a) Case 3: Helmholtz free energy model.

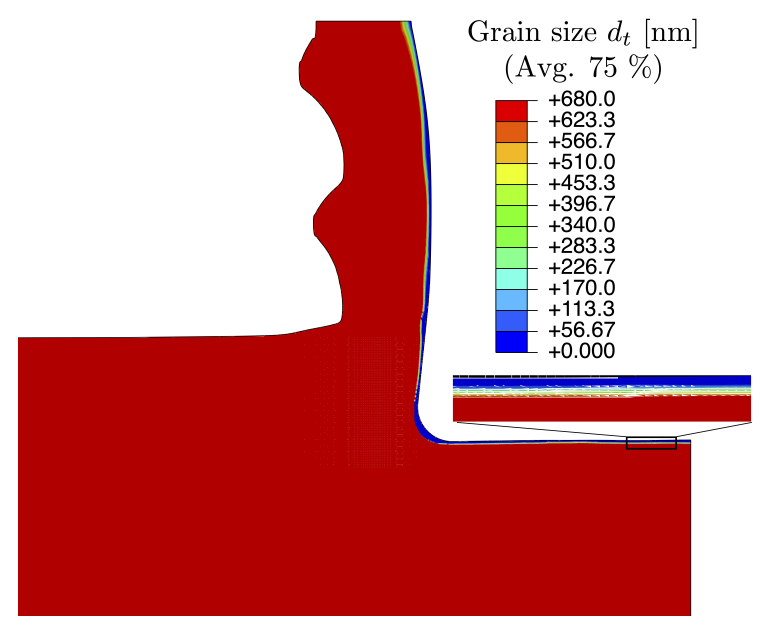

(c) Case 4: Helmholtz free energy model.

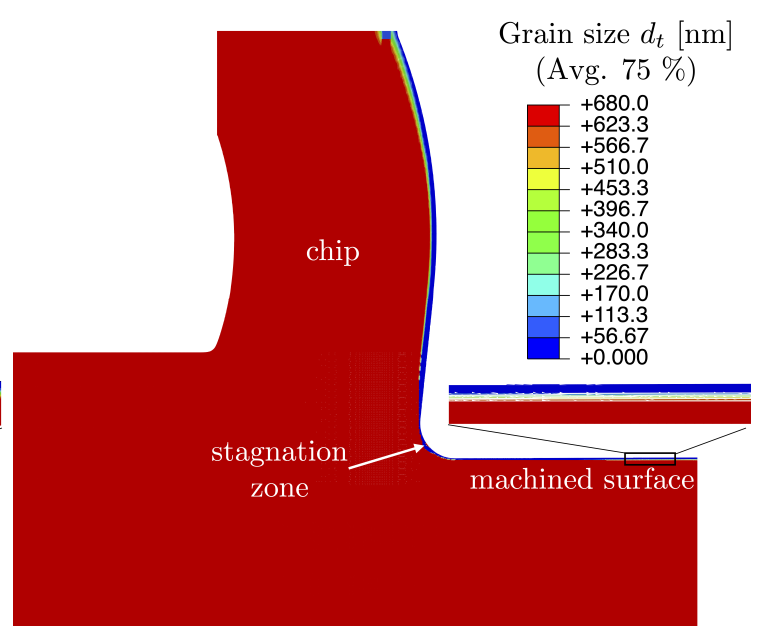

(b) Case 3: Zener-Hollomon model.

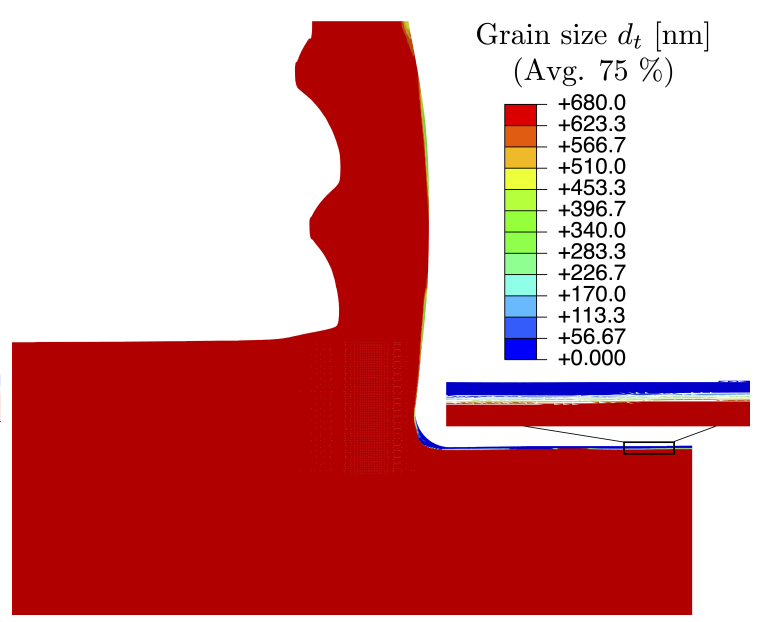

(d) Case 4: Zener-Hollomon model.

Figure 5. Prediction of grain size $d_{t}$ via Helmholtz energy and Zener-Hollomon models at investigated cases 3 and 4 .

As can be observed from Figures 4 and 5 different cutting conditions cause different chip geometries. Therefore, an additional experimental validation of the used CEL model regarding to chip thickness ratio (=chip thickness/undeformed chip thickness) is provided in Figure 6. From the diagram in Figure 6 it can be concluded that the presented Finite Element model was able to represent the chip thickness at higher cutting speed better than at lower cutting speed. In literature Ducobu et al., who compared the CEL and ALE methods when machining Ti6Al4V, also reported that the CEL method overestimates the chip thickness [45].

Figure 7 summaries the measured and with two different DRX models simulated thickness of the White Layer at various cutting conditions (see Table 7). Both Zener-Hollomon (ZH) and Helmholtz free energy (HE) models while slightly overestimated the White Layer thickness in Case 1 and 2, a perfect agreement was achieved in Case 3. In Case 4, however, a more pronounced deviation was observed between simulations and experiment. A reason for this result is the high cutting forces that were obtained in the simulation under the condition $v_{c}=150 \mathrm{~m} / \mathrm{min}$ and $h=0.2 \mathrm{~mm}$ (see Figure $3 \mathrm{a}$ ). 


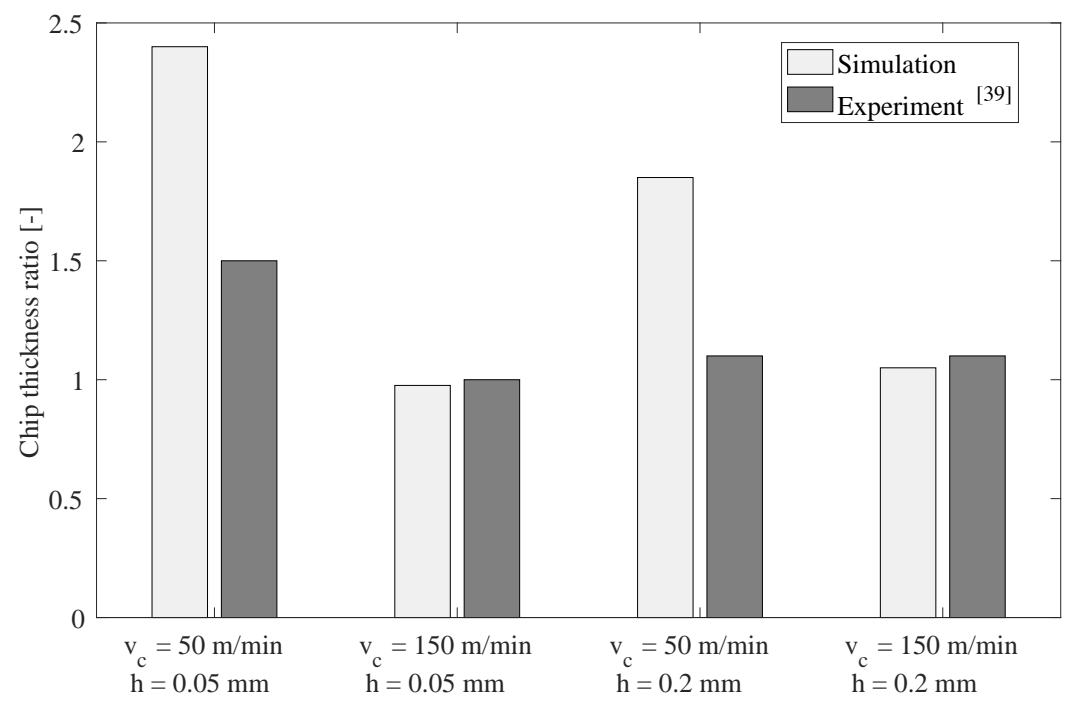

Figure 6. Experimental validation of chip thickness ratio.

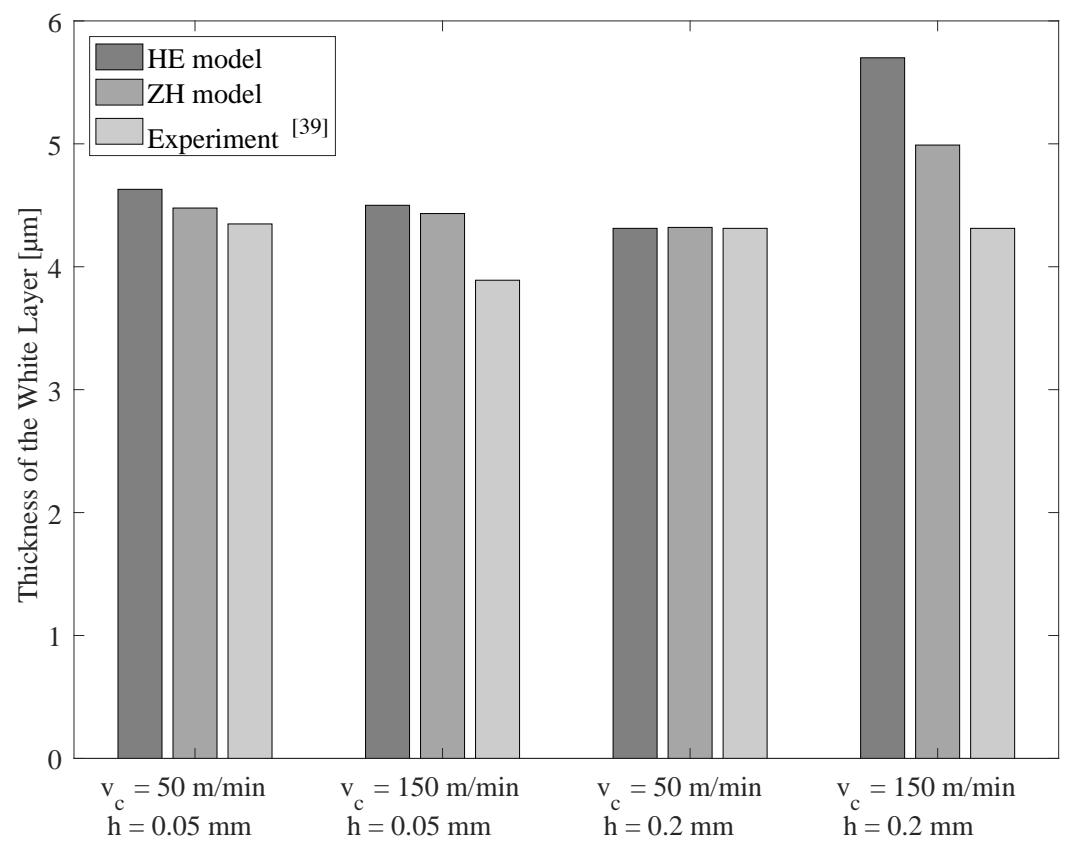

Figure 7. Predicted and experimentally measured White Layer thickness at different cutting conditions.

High cutting forces lead to higher temperatures and plastic strains on the machined surface and sublayer. This causes thicker White Layer due to the implemented DRX criteria $\bar{\varepsilon}^{p} \geq \bar{\varepsilon}_{c r i t}^{p}$ (ZH model) and $T \geq T_{\text {crit }}$ (HE model). Figure 7 indicated that the Zener-Hollomon model predicted the White Layer thickness slightly accurate than the Helmholtz free energy model. This can be explained by the many material constants which has to be fitted in case of $\mathrm{ZH}$ model in a time-consuming calibration procedure. Note that the whole depth of the dynamically recrystallized layer from the simulations where the grain size was smaller than the initial one was interpreted as a White Layer.

Figure 8 demonstrates the comparison of the predicted grain size evolution via Zener-Hollomon and Helmholtz free energy models on the workpiece rim zone after cutting in steady state with the experimental data. The path plots were created $0.4 \mathrm{~mm}$ behind the cutting tool after a step time of $5 \mathrm{~ms}$. It can be seen that both DRX models performed very similar results which were in good agreement with the experiments. Furthermore, Figure 8 illustrates that the Helmholtz free energy model delivered better correlations at lower undeformed chip thickness $(h=0.05 \mathrm{~mm})$, while Zener-Hollomon model 
showed better agreement at high cutting depth $(h=0.2 \mathrm{~mm})$. Note that grain growth was not considered in the simulations due to rapid cooling rates of the machined surfaces.
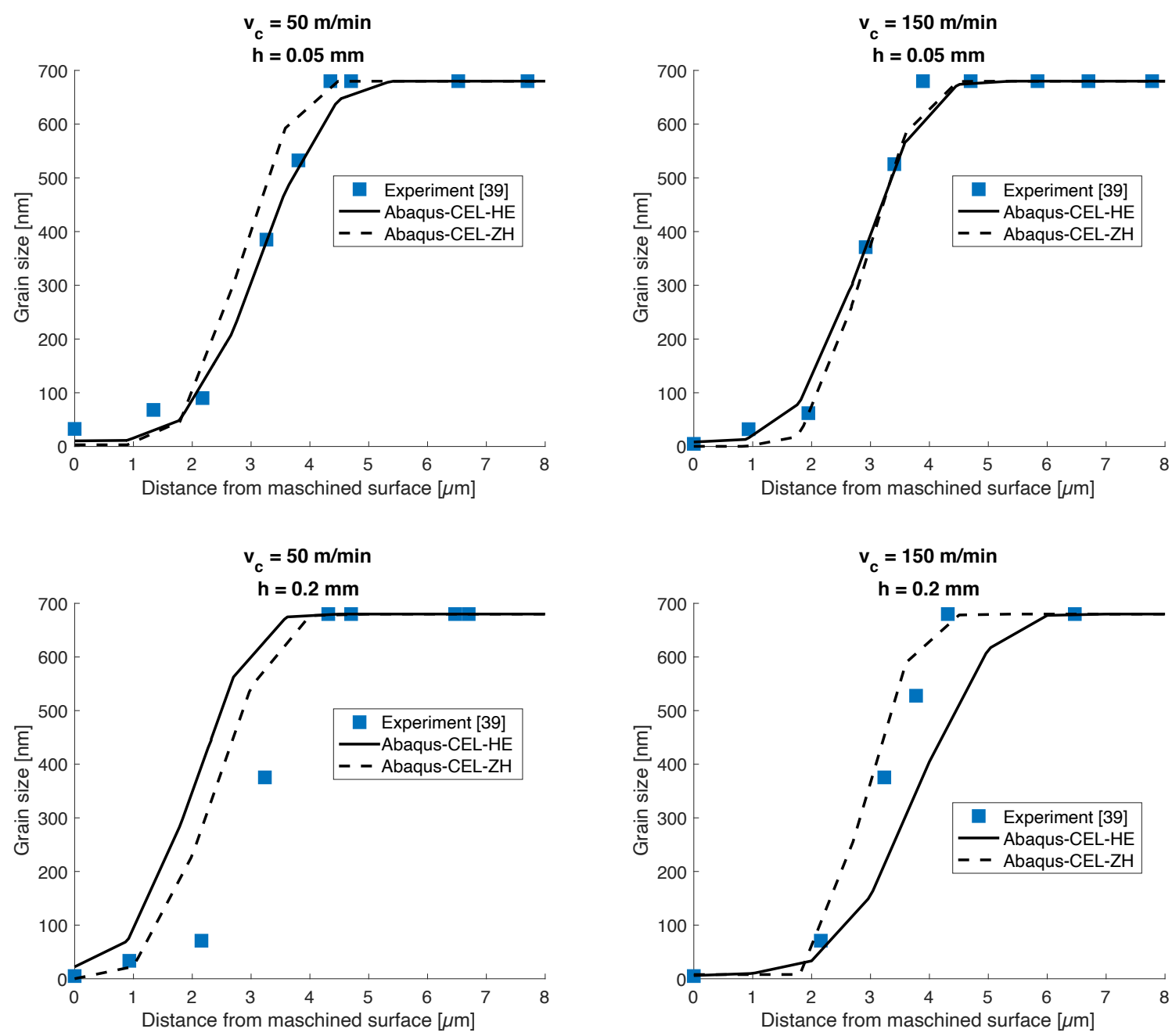

Figure 8. Comparison of the predicted and experimentally measured grain size evolution with Zener-Hollomon and Helmholtz energy models at different cutting speeds and undeformed chip thicknesses.

\section{Conclusions}

In this study, Helmholtz free energy and Zener-Hollomon models were implemented into Abaqus/Explicit 2018 to predict the workpiece rim zone modifications based on the Surface Integrity in form of White Layer formation due to dynamic recrystallization (DRX) during hard turning of quenched/tempered AISI 4140. The aim was to compare the results from both models to determine, which one is more suitable for the investigated material. In addition, a 3D model for orthogonal cutting was developed using the Coupled-Eulerian-Lagrangian approach. Both DRX models and Finite Element model were validated experimentally.

To conclude, although Zener-Hollomon model tended to show a slightingly closer match, both Helmholtz free energy and Zener-Hollomon models achieved a very good agreement regarding to the predicted and experimentally measured White Layer thickness as well as the grain size evolution on the machined surface.

In further investigations, an advanced material model with damage coupling, more DRX cases and an additional DRX model based on dislocation density will be analyzed. 
Author Contributions: Conceptualization B.T. and M.M.; methodology, B.T. and M.M.; software, B.T.; validation, B.T. and M.M.; resources, B.T. and M.M.; data curation, S.M.; writing-original draft preparation, B.T.; writing-review and editing, M.M. and S.M.; visualization, B.T.; supervision, S.M.; funding acquisition, S.M. All authors have read and agreed to the published version of the manuscript.

Funding: This research was funded by German Research Foundation (DFG) within the research priority program SPP 2086.

Acknowledgments: The scientific work has been supported by the German Research Foundation (DFG) within the research priority program SPP 2086. The authors would like to thank you Alexander Schowtjak for making his Python script available for the iterative calibration procedure of the Zener-Hollomon model. Simulations were performed with computing resources granted by RWTH Aachen University under project <rwth0466>.

Conflicts of Interest: The authors declare no conflict of interest.

\section{Abbreviations}

The following abbreviations are used in this manuscript:

$\begin{array}{ll}\text { ALE } & \text { Arbitrary-Lagrangian-Eulerian } \\ \text { CEL } & \text { Coupled-Eulerian-Lagrangian } \\ \text { DRX } & \text { Dynamic recrystallization } \\ \text { FEM } & \text { Finite Element Method } \\ \text { HE } & \text { Helmholtz energy } \\ \text { HRC } & \text { Rockwell hardness } \\ \text { IUL } & \text { Institut für Umformtechnik und Leichtbau } \\ \text { JC } & \text { Johnson-Cook } \\ \text { JMAK } & \text { Johnson-Mehl-Avrami-Kolmogorov } \\ \text { UL } & \text { Updated-Lagrangian } \\ \text { ZH } & \text { Zener-Hollomon }\end{array}$

\section{References}

1. Bartarya, G.; Choudhury, S. State of the art in hard turning. Int. J. Mach. Tools Manuf. 2012, 53, 1-14. [CrossRef]

2. Koch, K.F. Technologie des Hochpräzisions-Hartdrehens; Ph.D. Thesis, RWTH Aachen, Laboratorium fuer Werkzeugmaschinen und Betriebslehre, Aachen, Germany, 1996.

3. Klocke, F. Werkstückdynamik und Spannsysteme. In Fertigungsverfahren 1; Springer: Berlin/Heidelberg, Germany, 2018; pp. 501-510.

4. Sillekens, W.H.; Agnew, S.R.; Neelameggham, N.R.; Mathaudhu, S.N. (Eds.) Magnesium Technology 2011; John Wiley \& Sons, Inc: Hoboken, NJ, USA, 2011.

5. Jawahir, I.; Brinksmeier, E.; M'saoubi, R.; Aspinwall, D.; Outeiro, J.; Meyer, D.; Umbrello, D.; Jayal, A. Surface integrity in material removal processes: Recent advances. CIRP Ann. 2011, 60, 603-626. [CrossRef]

6. Borchers, F.; Clausen, B.; Eckert, S.; Ehle, L.; Epp, J.; Harst, S.; Hettig, M.; Klink, A.; Kohls, E.; Meyer, H.; et al. Comparison of Different Manufacturing Processes of AISI 4140 Steel with Regard to Surface Modification and Its Influencing Depth. Metals 2020, 10, 895. [CrossRef]

7. Griffiths, B.J. White Layer Formations at Machined Surfaces and Their Relationship to White Layer Formations at Worn Surfaces. J. Tribol. 1985, 107, 165-171. doi:10.1115/1.3261015. [CrossRef]

8. Ramesh, A.N.; Melkote, S. Modeling of white layer formation under thermally dominant conditions in orthogonal machining of hardened AISI 52100 steel. Int. J. Mach. Tools Manuf. 2008, 48, 402-414. [CrossRef]

9. Akcan, S.; Shah, W.S.; Moylan, S.P.; Chandrasekar, S.; Chhabra, P.N.; Yang, H.T.Y. Formation of white layers in steels by machining and their characteristics. Metall. Mater. Trans. A 2002, 33, 1245-1254. [CrossRef]

10. Umbrello, D. Influence of material microstructure changes on surface integrity in hard machining of AISI 52100 steel. Int. J. Adv. Manuf. Technol. 2011, 54, 887-898. [CrossRef]

11. Guo, Y.; Warren, A.; Hashimoto, F. The basic relationships between residual stress, white layer, and fatigue life of hard turned and ground surfaces in rolling contact. CIRP J. Manuf. Sci. Technol. 2010, 2, 129-134. [CrossRef] 
12. Buchkremer, S.; Klocke, F.; Döbbeler, B.; Abouridouane, M.; Meurer, M. Thermodynamics-based Interpretation of White Layer Formation in Metal Cutting. Procedia CIRP 2017, 58, 370-374. [CrossRef]

13. Ulutan, D.; Özel, T. Machining induced surface integrity in titanium and nickel alloys: A review. Int. J. Mach. Tools Manuf. 2011, 51, 250-280. [CrossRef]

14. Umbrello, D.; Filice, L. Improving surface integrity in orthogonal machining of hardened AISI 52100 steel by modeling white and dark layers formation. CIRP Ann. Manuf. Technol. 2009, 58, 73-76. [CrossRef]

15. Zhang, F.Y.; Duan, C.Z.; Wang, M.J.; Sun, W. White and dark layer formation mechanism in hard cutting of AISI52100 steel. J. Manuf. Process. 2018, 32, 878-887. [CrossRef]

16. Brown, M.; Ghadbeigi, H.; Crawforth, P.; M'Saoubi, R.; Mantle, A.; McGourlay, J.; Wright, D. Non-destructive detection of machining-induced white layers in ferromagnetic alloys. Procedia CIRP 2020, 87, 420-425. [CrossRef]

17. Yada, H.; Matsuzu, N.; Nakajima, K.; Watanabe, K.; Tokita, H. Strength and Structural Changes under High Strain-rate Hot Deformation of C Steels. Trans. Iron Steel Inst. Jpn. 1983, 23, 100-109. [CrossRef]

18. Yanagimoto, J.; Karhausen, K.; Brand, A.J.; Kopp, R. Incremental Formulation for the Prediction of Flow Stress and Microstructural Change in Hot Forming. J. Manuf. Sci. Eng. 1998, 120, 316. [CrossRef]

19. Estrin, Y.; Tóth, L.S.; Molinari, A.; Bréchet, Y. A dislocation-based model for all hardening stages in large strain deformation. Acta Mater. 1998, 46, 5509-5522. [CrossRef]

20. Fanfoni, M.; Tomellini, M. The Johnson-Mehl- Avrami-Kohnogorov model: A brief review. Il Nuovo Cimento D 1998, 20, 1171-1182. [CrossRef]

21. Buchkremer, S.; Klocke, F. Modeling nanostructural surface modifications in metal cutting by an approach of thermodynamic irreversibility: Derivation and experimental validation. Contin. Mech. Thermodyn. 2017, 29, 271-289. [CrossRef]

22. Umbrello, D.; Hua, J.; Shivpuri, R. Hardness-based flow stress and fracture models for numerical simulation of hard machining AISI 52100 bearing steel. Mater. Sci. Eng. A 2004, 374, 90-100. [CrossRef]

23. Caruso, S.; Di Renzo, S.; Umbrello, D.; Jayal, A.D.; Dillon, O.W.; Jawahir, I.S. Finite Element Modeling of Microstructural Changes in Hard Turning. Adv. Mater. Res. 2011, 223, 960-968. [CrossRef]

24. Ambrosy, F.; Zanger, F.; Schulze, V. FEM-simulation of machining induced nanocrystalline surface layers in steel surfaces prepared for tribological applications. CIRP Ann. 2015, 64, 69-72. [CrossRef]

25. Arısoy, Y.M.; Özel, T. Prediction of machining induced microstructure in Ti-6Al-4V alloy using 3-D FE-based simulations: Effects of tool micro-geometry, coating and cutting conditions. J. Mater. Process. Technol. 2015, 220, 1-26. [CrossRef]

26. Baik, S.C.; Hellmig, R.J.; Estrin, Y.; Kim, H.S. Modeling of deformation behavior of copper under equal channel angular pressing. Z. Für Met. 2003, 94, 754-760. [CrossRef]

27. Ding, H.; Shin, Y. Dislocation Density-Based Grain Refinement Modeling of Orthogonal Cutting of Titanium. J. Manuf. Sci. Eng. 2014, 136. [CrossRef]

28. Ding, L.; Zhang, X.; Richard Liu, C. Dislocation Density and Grain Size Evolution in the Machining of Al6061-T6 Alloys. J. Manuf. Sci. Eng. 2014, 136. [CrossRef]

29. Atmani, Z.; Haddag, B.; Nouari, M.; Zenasni, M. Combined microstructure-based flow stress and grain size evolution models for multi-physics modelling of metal machining. Int. J. Mech. Sci. 2016, 118, 77-90. [CrossRef]

30. Li, B.; Zhang, S.; Hu, R.; Zhang, X. Dislocation density and grain size evolution in hard machining of H13 steel: Numerical and experimental investigation. J. Mater. Res. Technol. 2020. [CrossRef]

31. Ding, H.; Shin, Y.C. Multi-physics modeling and simulations of surface microstructure alteration in hard turning. J. Mater. Process. Technol. 2013, 213, 877-886. [CrossRef]

32. Zhang, W.; Zhuang, K. Effect of cutting edge microgeometry on surface roughness and white layer in turning AISI 52100 steel. Procedia CIRP 2020, 87, 53-58. [CrossRef]

33. Neslušan, M.; Uríček, J.; Mičietová, A.; Minárik, P.; Píška, M.; Čilliková, M. Decomposition of cutting forces with respect to chip segmentation and white layer thickness when hard turning 100Cr6. J. Manuf. Process. 2020, 50, 475-484. [CrossRef]

34. Augspurger, T.; Meurer, M.; Liu, H.; Mattfeld, P.; Bergs, T. Experimental study of the connection between process parameters, thermo-mechanical loads and surface integrity in machining Inconel 718. Procedia CIRP 2020, 87, 59-64. [CrossRef] 
35. Meurer, M.; Tekkaya, B.; Augspurger, T.; Pullen, T.; Schraknepper, D.; Bergs, T.; Münstermann, S. Cutting Force based Surface Integrity Soft-Sensor when Hard Machining AISI 4140. TM Tech. Mess. 2020, accepted.

36. Meurer, M.; Augspurger, T.; Tekkaya, B.; Schraknepper, D.; Lima, A.P.; Bergs, T. Development of a Methodology for Strain Field Analysis during Orthogonal Cutting. Procedia CIRP 2020, 87, 444-449. [CrossRef]

37. Johnson, G.R.J.P.t.I.S.B. A constitutive model and data for materials subjected to large strains, high strain rates, and high temperatures. In Proceedings of the 7th International Symposium on Ballistics, Hague, The Netherlands, 19-21April 1983; pp. 541-547.

38. Hughes, G.D.; Smith, S.D.; Pande, C.S.; Johnson, H.R.; Armstrong, R.W. Hall-petch strengthening for the microhardness of twelve nanometer grain diameter electrodeposited nickel. Scr. Metall. 1986, 20, 93-97. [CrossRef]

39. Buchkremer, S. Irreversible Thermodynamics of Nano-Structural Surface Modifications in Metal Cutting. PhD. Thesis, RWTH Aachen; IIF-Institut für Industriekommunikation und Fachmedien GmbH, Aachen, Germany, 2017.

40. Liu, Y.; Agmell, M.; Xu, D.; Ahadi, A.; Stahl, J.E.; Zhou, J. Numerical contribution to segmented chip effect on residual stress distribution in orthogonal cutting of Inconel718. Int. J. Adv. Manuf. Technol. 2020, 109, 993-1005. [CrossRef]

41. Agmell, M.; Bushlya, V.; Laakso, S.V.A.; Ahadi, A.; Ståhl, J.E. Development of a simulation model to study tool loads in pcBN when machining AISI 316L. Int. J. Adv. Manuf. Technol. 2018, 96, 2853-2865. [CrossRef]

42. Laakso, S.V.A.; Zhao, T.; Agmell, M.; Hrechuk, A.; Ståhl, J.E. Too Sharp for its Own Good - Tool Edge Deformation Mechanisms in the Initial Stages of Metal Cutting. Procedia Manuf. 2017, 11, 449-456. [CrossRef]

43. Nordgren, A.; Samani, B.Z.; Saoubi, R.M. Experimental Study and Modelling of Plastic Deformation of Cemented Carbide Tools in Turning. Procedia CIRP 2014, 14, 599-604. [CrossRef]

44. Guo, Y.B.; Wen, Q. A hybrid modeling approach to investigate chip morphology transition with the stagnation effect by cutting edge geometry. Trans. N. Am. Manuf. Res. Inst. SME 2005, 33, 469-476.

45. Ducobu, F.; Riviere, E.; Filippi, E. Application of the Coupled Eulerian-Lagrangian (CEL) method to the modeling of orthogonal cutting. Eur. J. Mech. A/Solids 2015, 59, 58-66. [CrossRef] 